\title{
Anestesia subaracnoidea continua en paciente embarazada con percretismo placentario
}

\author{
Muñoz LM. ${ }^{1}$, Presinky MN. ${ }^{1}$ \\ 1 Hospital Luis Carlos Lagomaggiore, Mendoza, Argentina.
}

Introducción: El acretismo placentario es la adherencia anómala de la placenta en el miometrio, el percretismo incluye la invasión extrauterina a órganos contiguos. El creciente número de cesárea aumenta su incidencia, el riesgo de sangrado perioperatorio y la morbimortalidad materno-fetal.

Descripción del caso: Paciente femenina, 35 años de edad, ASA II, 3 gestas, 2 cesáreas, cursando embarazo de EG 34 semanas, con antecedentes de extabaquismo, enfermedad celíaca, depresión y anemia. Se realizó RMN donde se diagnosticó placenta previa oclusiva total con percretismo placentario. Se decidió colocar catéter peridural previo a balonización de arterias uterina y luego cesárea e histerectomía programada. Se recibe paciente en quirófano el día previo a la cirugía para colocación de catéter peridural, durante realización de técnica de pérdida de resistencia se evidencia salida de LCR a los 3,5 cm de piel, se decide colocar catéter subaracnoideo y tunelizar para posterior anestesia por dicho catéter. Al día siguiente se recibe paciente en quirófano, se monitoriza con oximetría de pulso, tensión arterial no invasiva e invasiva, ECG continuo, se colocan 2 vías periféricas de grueso calibre (16G), profilaxis antibiótica y antiemética, Ácido tranexámico $1 \mathrm{~g}$, se realiza prueba de catéter subaracnoideo con $3 \mathrm{mg}$ de bupivacaína hiperbárica, se evalúa con prueba frio-calor y estímulo doloroso el nivel de bloqueo (T12), pasado 5 minutos se colocan otros $5 \mathrm{mg}$ de bupivacaína hiperbárica con $20 \mathrm{mcg}$ de fentanilo y se constata bloqueo a nivel de T6. Se procede a la realización de cesárea, se extrae recién nacido vigoroso, luego se procede a histerectomía, durante las 3 h de cirugía se realiza reinyección de $3 \mathrm{mg}$ de bupivacaína hiperbárica a las $2 \mathrm{~h}$ de la primera inyección, se expande con $4 \mathrm{~L}$ de cristaloides y se transfunde una UGR, diuresis de 1 L.,TA 110-85/60-55 mmHg, saturación de oxígeno 97-99\%, perdida estimada de sangre $2 \mathrm{~L}$, previo a finalizar cirugía se administra $8 \mathrm{mg}$ de ondansetrón, $2 \mathrm{~g}$ dipirona y $100 \mathrm{mcg}$ de morfina por catéter subaracnoideo. Se evalúa escala de Bromage 100\% bloqueo motor, Ramsay II/VI, compensada hemodinámicamente se traslada a cuidados intensivos.

Comentarios y Discusión: En relación a anestesiología: la cesárea en pacientes con acretismo placentario implica un manejo anestésico minucioso por el riesgo de shock hipovolémico, la técnica de anestesia subaracnoidea continua es una técnica anestésica segura, generando mínimos cambios hemodinámicos durante la cirugía y dando la posibilidad de un primer contacto madre-hijo.

https://doi.org/10.25237/congresoclasa2019.53 